\title{
THE CUlTURAL SIGNIFICANCE OF THE SPIRAL
}

\section{David Anderson}

Such is its creative force, the Spiral exists in ways that are more real than many contemporary buildings that have already been built and stand unnoticed. The Victoria and Albert Museum's thinking and its programmes are being drawn forward by the Spiral's gravitational pull. The Spiral cannot now be unthought, and the Museum moves in response to the momentum it has generated.

\section{Audience Development}

Access can be defined in terms of equality of opportunity, or of equality of outcome. The success of the Spiral will be measured by the outcome, the change it achieves in the V\&A's audience. The principal barriers to access are social or educational disadvantage, poverty, ethnic and cultural exclusion, disability and an individual's own attitudes. These factors often operate in combination, so that a successful strategy to overcome them will require a co-ordinated programme.

Whatever their background, people will only visit the Spiral if they believe they will be able to participate in it in the ways that they find interesting and enjoyable. For some people, participation means quiet, personal engagement with an object or work of art, but others may want to participate through social and practical activities.

Non-users of museums often regard them as gloomy and boring. Both non-users and infrequent users tend to value above all the social aspect of their leisure activities, and believe that children are the main reason for going to museums; these people want lively activities. Children, sociability, comfort and practicality will, therefore, be a priority for the Spiral in attracting significant numbers of those who are non-visitors at present.

The V\&A's aim is also to encourage more people to become self-sustaining users of the Museum. People of all ages, from childhood to old age, need museums such as the V\&A to provide them with stepping stones to new skills and experiences. The emphasis in the early stages must be on instilling interest and enthusiasm, developing later to more demanding activities for those people who have greater assurance and self-confidence. The challenge for the Spiral will be to provide these stepping stones for visitors of very varied interests, skills, confidence and cultural backgrounds.

Opening hours can be another obstacle to access. The Spiral will, so far as possible, be open beyond standard museum hours, an- 
86 other change that is in fact merely a reversion to the museum's practice in the nineteenth century, when it opened in the evenings to enable working people to visit.

The Spiral will provide the V\&A with public space of a kind that it does not presently possess. The concept of public space is one which currently is the subject of extensive enquiry and debate on the part of social geographers, art historians, anthropologists and specialists from other academic disciplines. The values, codes of morality and expectations of behaviour established by the V\&A in the Spiral will help to shape those of the public. The Spiral's willingness to embrace diversity, and to remove barriers to access, will establish norms for the public. The Spiral will also have an important role in defining public notions of quality, including aesthetic quality, and will show that museums can serve as places of debate, informed discussion, and expression of public feeling. This responsibility cannot be evaded.

The V\&A will base its relationship with the public in part on the concept of "common-sense," as defined by the Scottish philosopher George Davie - that is, the notion that the expertise of the professional is accountable to and works in partnership with the educated understanding and generalist judgement of the wider public. ${ }^{1}$ The Spiral will (within constraints of resources and the protection of objects) give the public the choice and opportunity to decide for themselves how to use V\&A resources, rather than the institution decide for them.

Daniel Libeskind has stressed the importance of the Spiral as a place for cross-cultural experiences for a multi-cultural society. The Spiral, both in its design and its programmes, will reflect the cultural diversity of the
V\&A's collections. The fractal tiles which will clad the exterior, for example, draw inspiration from the designs of Isfahan and Granada. Cross-culturalism will be a thread running through the project from audience research in the feasibility studies, the involvement of artists in the construction of the building, and the programmes and exhibitions offered by the site after opening. The Spiral will promote cultural literacy - skills which are essential for participation in a pluralistic society.

The project will be informed by Henri Lefebvre's distinction between "conceived" (intellectual, abstract, "cool") spaces and "lived" (passionate, sensual, "hot") spaces, and will seek to provide both. It will also draw upon research into everyday life by Michel de Certeau among others, and will extend Libeskind's metaphor of the V\&A as a secret city by involving those who explore the issues of experiencing and interpreting the city; the Spiral and the V\&A operate on such a scale as to make the concept of the museumcity not just a metaphor but also some kind of reality. The Spiral will be a new arts centre for the museum-city and also an arts centre for the South Kensington area as a whole. ${ }^{2}$

The Spiral's programme will represent a manifesto for change in the V\&A, and a counter-museum in critical dialogue with its larger and more traditional companion. The Spiral is not in this respect an intrusive innovation - rather it will represent and make manifest a significant creative yet subordinate tradition that has existed at the V\&A from its foundation. The differences between the Spiral and the rest of the V\&A will in any case be a matter of degree as much as anything else, as objects, methodologies and staff flow between the two. The establishment of 
this dialogue will be a continuing source of creative energy for the institution.

The development of alternative rationales for the V\&A's subject and collections is vital if the museum is to attract new audiences. The exclusion of significant areas of nonWestern art, craft and design in the V\&A is solely the consequence of 19 th century imperial value judgements that were indefensible in the twentieth century and are utterly unacceptable in the twenty-first. The museum's past disregard for product design marginalised it from many of the most significant developments in the field for over a century. The separation of science and art, the historian of the V\&A Anthony Burton has pointed out, was in the mid-nineteenth century a division between understanding and practice, not between disciplines as they are currently understood; the consequence of the V\&A's disregard for practice was the physical and intellectual isolation of the Museum from the field of enquiry it represents. ${ }^{3}$

In the nineteenth century the Museum had the confidence to define its purpose and subject broadly and inclusively, with the explicit aim of extending its public reach. This ambition died almost entirely in the twentieth century. Significantly, Bethnal Green Museum was changed in the 1970s from a missionary branch of the V\&A as a museum of art and design in the East End of London, to the site of exile for a then low status dimension of the V\&A's collections - toys and the artefacts of childhood (ironically, these are now both popular and academically significant). Likewise, the potential that a focus on music, the voice, the body and movement, which the performing arts could have brought to interpretation at the South Kensington site, was also diminished when the theatre collections were located in Covent Garden. Through many of these changes, the Museum seemed more effective at defining in its own restrictive terms what the arts were not, rather than making a positive statement of what in contemporary society they should be.

Starting out, albeit naively and paternalistically, with the aim of being a museum for ordinary people, in practice the V\&A became by the early twentieth century a museum mainly for the elite. It was not popular or loved, even in the rather passive and undemanding way that the National Gallery was loved by many people, and it reaped the consequences of this in declining visitor numbers. Until recently, popular culture and contemporary design were addressed only fitfully and in an uncoordinated way. The Museum had turned its back on some of its core constituencies and upon society itself. Intellectually, socially and politically, with only intermittent flashes of exception, it had cut itself off from daily life for most members of the public. The Museum was in danger of becoming the museological equivalent of the "superfluous man" who featured so frequently in nineteenth century Russian novels, an institution without any social purpose.

From this perspective, the Spiral is the culminating act in a process of institutional renewal that has gone on since the 1980s. It will include art and design from all cultures. It will be a centre for all forms of contemporary arts, with historical material taking a subordinate and supporting role. It will represent all art forms - including digital technologies and the performing arts - as resources for display as well as media of interpretation.

There is currently extensive debate about the kind of knowledge needed by society at the beginning of the twenty-first century. It 
88 is no accident that the challenge to traditional disciplines and formal practices has come principally from the cultural and social sectors of the economy, where the new approaches are seen as critical for achieving commercial success and winning community support. Reflexive and socially accountable thinking, it is intended, will underpin the process of development of the Spiral, as well as its operation after opening. In this, the Spiral will contribute to a reassertion of the distinctive intellectual contribution of the arts, and the essential role in wealth creation played by the creative industries and the cultural sector (now the fourth largest part of the UK economy, and the fastest growing).

\section{The Spiral as a Creative space}

According to the Crafts Council in London, "Making is a creative process that develops practical, conceptual and visual skills through personal engagement with tools and materials in response to human needs." ${ }^{4}$ The Spiral will provide a public space for the creative activities of established or emerging artists and designers in all media. It will be a space for scholarships and fellowships, for private research and the development of skills by these same practitioners. It will commission art works from practitioners to fit out and decorate the Museum and its buildings - as the V\&A has done since its foundation (recently asking Danny Lane to design a balustrade in the Glass Gallery and Wendy Ramshaw to make a wrought iron screen for the staff restaurant). The Spiral might even, as in the nineteenth century, use the skills of prisoners and students to decorate its floors and ceilings! The Spiral with its associated Learning Centre will provide the V\&A with much needed practical arts education workshops - as well as activity spaces amongst the galleries - so that the public of all ages and levels of skill can participate in the making process.

The Spiral's programme will encourage collaborations between practitioners in different media such as design, performance, broadcasting and multi-media, and the crossfertilisation of disciplines. It will encourage independent "producers" of exhibits, and will play an active role, through the shops and exhibitions and events as well as provision of on-line arts activities and resources, in the diffusion of creative work. The Spiral will attempt to invigorate the contemporary creative agenda, and by doing so to reassert the V\&A's former role in the mid nineteenth century as a centre for cutting edge debate and practice in the arts.

As Anthony Burton has said, "The ability to make imaginative constructions, and to realise them in words, or in music, or in more concrete form as objects or pictures, is found in all sorts and conditions of people." Shamiana - an exhibition of textiles created by Arian women's groups which was displayed at the V\&A in 1997, demonstrated the capacity of members of the public, given appropriate encouragement and support, to create works of art of exceptional freshness and beauty. This project, highly successful though it was, nevertheless suffered from lack of appropriate facilities. The Spiral will ensure that similar projects in the future will be much easier to implement. The bringing together of practitioners and public in creative space is a fundamental principle of the project.

Hans Eysenck has identified twelve variables affecting creative production. Four of these, he proposes, are cognitive (intelligence, knowledge, technical skills, special talents). 


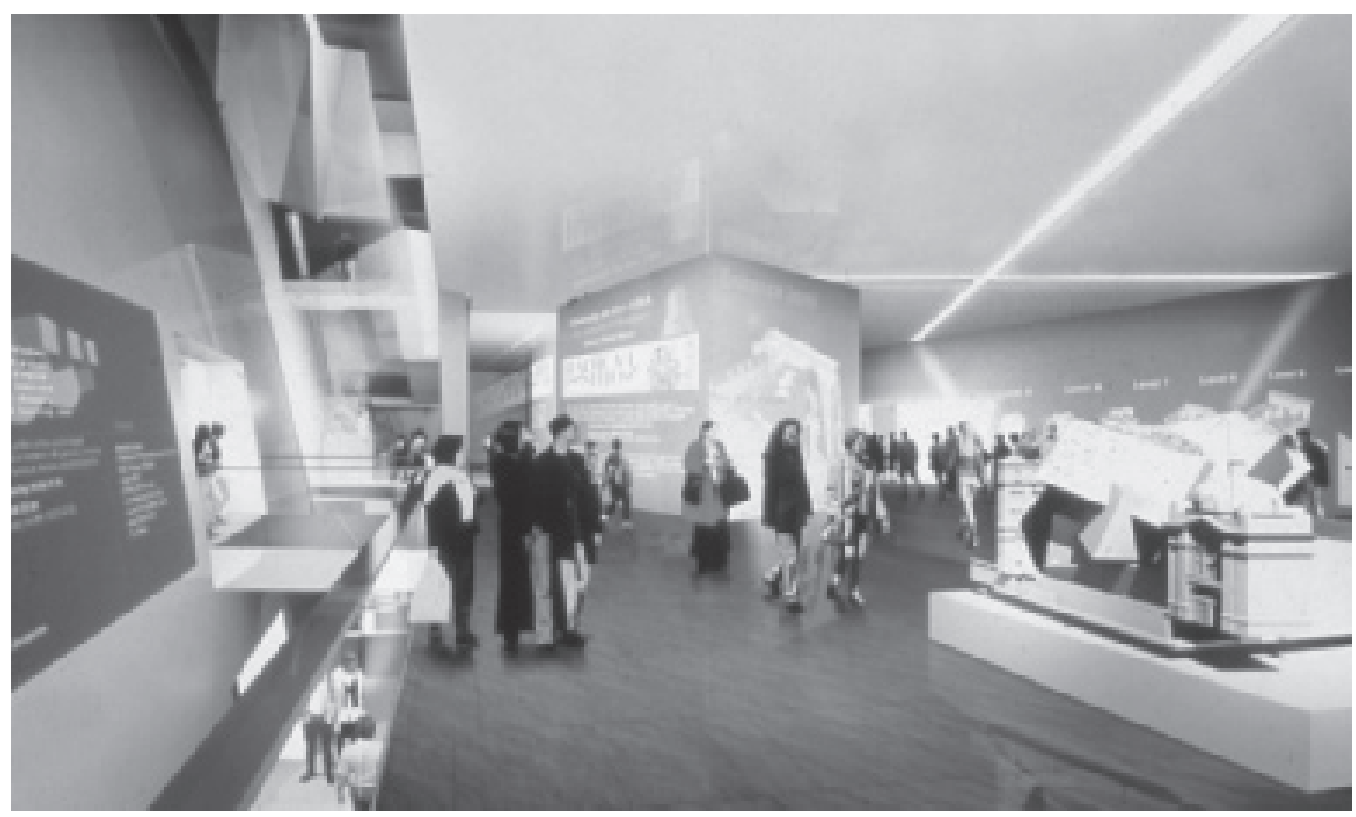

Photo montage of Spiral interior showing Level 1. (C) Miller Hare 2001.

Four are environmental (politico-religious factors, cultural factors, socio-economic factors and educational factors). Four are variables related to personality (internal motivation, confidence, non-conformity, and finally, creativity as a trait). Eysenck, in analysing research on the creative personality, found that there was a correlation between creativity endeavour and certain psychopathologies (schizophrenia in the case of artists, manic-depression in the case of scientists). ${ }^{5}$ Eysenck's work, and a range of other studies, such as those by Mihaly Csikszentmihalyi, ${ }^{6}$ have identified that creative personalities are more likely than uncreative personalities to be independent in attitude and social behaviour, dominant, introverted, open to stimuli, wide-ranging in their interests, self-accepting, intuitive, flex- ible, possessing social presence and poise, asocial in attitude, unconcerned for social norms, radical, and rejecting social constraints. They are also more likely to be unstable, irresponsible, disorderly, rebellious, uncontrolled, self-seeking, tactless, intemperate, rejecting of rules, uncooperative, impulsive and careless - as well as possessing many positive characteristics such as tolerance and spontaneity.

It is evident, if this extensive research evidence is accepted, that there could be conflict between the culture of a large public museum and the kind of environment required to enable creative personalities to translate their potential into useful life-enhancing and/or saleable creative products. It is also evident that Libeskind and Balmond are attempting to build a structure which will provide the 
90 kind of environment which will encourage creativity. The Spiral will be, again, a mediating third-space between the V\&A and creative practitioners which the Museum (and probably many other museums) needs.

A valuable analysis of creativity has been developed by Professor Leslie Perry of London's Institute of Education. Pointing out that the word has become so loaded with meanings, positive and negative, in support or contradiction of so many arguments, that many people will not use it, he argues instead that it must be clarified and rehabilitated. The full educational value of the arts, he says, cannot be appreciated without it. Rejecting both the free play-centred definition of certain progressive educators, and the "dispensable and indulgent luxury" caricature of conservative advocates of the purely knowledge-based curriculum, he suggests that "a frame of mind where people lay aside routine responses and open themselves to new understanding and new insight and a new relation to the medium in which they are working is indispensable if an individual response and not a standardised response is to appear". But he adds that "past creativity is preserved and brought into a continuity with present creativity by knowledge well learnt."7

Perry has challenged the work-leisure distinction which is sometimes used to marginalise education for creativity. He argues that there is no shred of evidence to substantiate the viewpoint that creative capabilities are useful only for cultivation of leisure, whilst the "cognitive" capabilities are the real introductions to work and vocations. He also rejects the view that the cultivation of (cognitive) mental powers is concentrated in some disciplines and present only in small measure in others (such as art or craft). Perry sums up by identifying that creativity provides the potential for an optimal motivational state, optimal mental and physical activity, and optimal results, across all disciplines.

An issue related to, and as debated as, that of creativity is that of visual literacy, which was the subject of a recent Arts Council of England report by Karen Raney. The term "visual literacy" invites comparison with verbal literacy, and implies a set of skills with ascending levels of competence - an approach which many have challenged, because it suggests that visual response is something measurable, rather than something involving "passion, perplexity, fear or delight" or assumption, belief and expectation. One can be a "fluent looker," at three years of age, Raney says in a way that it is impossible to be a fluent reader. ${ }^{8}$

Opinion from Raney's interviews with arts practitioners was unanimous that the objects of study of the visual need to be as wide ranging as possible: from youth culture and computer games to film, home decor, eating utensils and art and artefacts of all kinds. Also that "making" needs to be defined as broadly and as inclusively as possible - not just drawing and painting, but photography, digital imaging, collage, fashion, craft and design (and, one might add, performance, graphic arts, architecture etc). The scope of visual literacy is visual culture, not visual art, all agreed. Many respondents felt that the art and nonart distinctions are now so problematic that they should be put aside, except as a (culturally and historically) separate Western phenomenon. "It depends on whether you're teaching about ART, or whether you're teaching kids to look. My preference is for the latter," said one of Raney's interviewees, "Art is that cultural space where complex things are 
explored," said another. And another, it is important to research the entire range of visual culture, but important to attend to the specificity of different regimes of representation." If this consensus view is accepted, the Spiral will need to address the full range of visual culture across the full range of making, if it is to place itself at the centre of the creative economy and the critical debates that relate to it.

What are the characteristics and requirements of a creative space? Mihaly Csikszentmihalyi, in Creativity: Flow and the psychology of discovery and invention, has attempted to answer this question through qualitative studies. He concludes that what sets creative individuals apart is that, regardless of their environment, they manage to give their surroundings a personal pattern that echoes the rhythm of their thoughts and habits. Beyond this, creative people gravitate to places where the richness of resources, the critical mass of other creative individuals in one's field who are prepared to be both critical and supportive, and the money which buys freedom to experiment, are all available. There is no evidence that a beautiful setting in itself stimulates creativity, although a change to novel and complex settings seems to do so. ${ }^{9}$ Research institutions which have become legendary for their ability to nurture important innovations provide freedom of action and the stimulation of ideas. Many of them are also places of very diverse concepts and disciplines, where the contact and interaction of these in itself seems to encourage creativity. The challenge for the Spiral will be to provide an environment in which the conditions for creativity on the part of both practitioners and the public are met.

Another trend of direct relevance to the
Spiral and the V\&A is the increasing realisation of the contribution of the cultural sector to the economic, social and educational developments of society. Central to the United Kingdom Government's vision is the National Endowment for Science, Technology and the Arts (NESTA). NESTA owes its genesis to a perception that the UK has "an astonishing track record of generating good ideas in almost every area of the arts, science and technology but an abysmal one when it comes to developing those good ideas onto the next stage" according to Chris Smith, formerly Secretary of State at the Department for Culture, media and sport. ${ }^{10}$ Specifically, NESTA is working with other bodies to help talented individuals to develop their full potential in the creative industries, science and technology; turn creativity and ideas into products and services which are effectively exploited with rights effectively protected; advance public education about, and awareness and appreciation of, the creative industries, science, technology, and the new art forms, and their contribution to the quality of life.

The new Spiral could contribute to the achievement of NESTA's goals, contributing to the training and development of young artists, craftspeople, designers and other practitioners at the beginning of their careers; working to reduce the barriers between the arts and the sciences; and promoting public engagement with contemporary design. In the world of the "weightless economy" the Spiral will be a space for the creative development of ideas and for investment in their dissemination.

Many issues remain. If the Spiral aims to foster greater creativity in society, how should its success in this be measured? How can the differences in norms of creativity between 
92 Western and non-Western cultures - particularly those societies in which working within an artistic and cultural tradition is highly valued - be addressed by the building and its programme? What exactly is the creative process? Is it possible for public education and professional practice to co-exist side-by-side?

The Spiral will, then, aim to be a space for exhibiting the products of creativity. But it will also be a potent and visible symbol in built form of the value of trans-disciplinary creativity; a place for on-site creativity for professional and non-professional artists makers and designers, and interchange between them; and a place for the wider creative process in society.

\section{The SPIRAL}

\section{AS A CENTRE FOR PUBLIC LEARNING}

Learning is, according to the definition developed by the Campaign for Learning in the United Kingdom, "a process of active engagement with experience. It is what people do when they want to make sense of the world. It may involve an increase in skills, knowledge and understanding, values and the capacity to reflect. Effective learning leads to change, development and the desire to learn more."

A European Forum organised by the United Kingdom Museums and Galleries Commission in Liverpool in 1998 proposed a definition of a museum "as a framed experience rooted in authenticity". This basic concept shapes the Spiral's educational philosophy, and will define its educational work.

Until the mid 19th century, art was a skill or practical ability - "doing" - whereas science was "knowing". The creation by Henry Cole of a Department of Science and Art, and within it the South Kensington Museum in which both disciplines were combined, was in three respects a significant step. First, it asserted the necessity of combining "doing" and "knowing" and that each was dependent upon the other as mutually supporting processes, and as the basic components of learning. Second, it recognised the interdependence of learning and culture (here used in its broader, anthropological sense). And, third, it acknowledged that central government, on behalf of the public, had a direct responsibility for promoting the development of learning and culture for the benefit (in this case primarily industrial and social) of society.

In its early days the V\&A was also very deliberately created to reach the mass of the working population. The radicalism of this is often forgotten. In 1848, when the Chartists had marched on London, the British Museum, as a bastion of the establishment, feared that it would become a target for the protesters. Barricades were built around the entrances, and the staff were armed and sworn in as special constables. For Henry Cole, less than a decade later in 1857 to say, in his inaugural speech as the first Director of the South Kensington Museum (the predecessor of the V\&A), that "this museum will be like a book with its pages open, and not shut", and an institution dedicated to public education, was an act of extraordinary radicalism, a great experiment. ${ }^{11}$ It was also an act of faith in the power of objects to move people's hearts and minds. The V\&A is, then, a museum based on an educational idea: that of the central importance of experience.

To what extent is the V\&A's original educational purpose still of relevance to us today? This is a legitimate question, particularly in the wake of the separation of the South Kensington Museum into its two component 


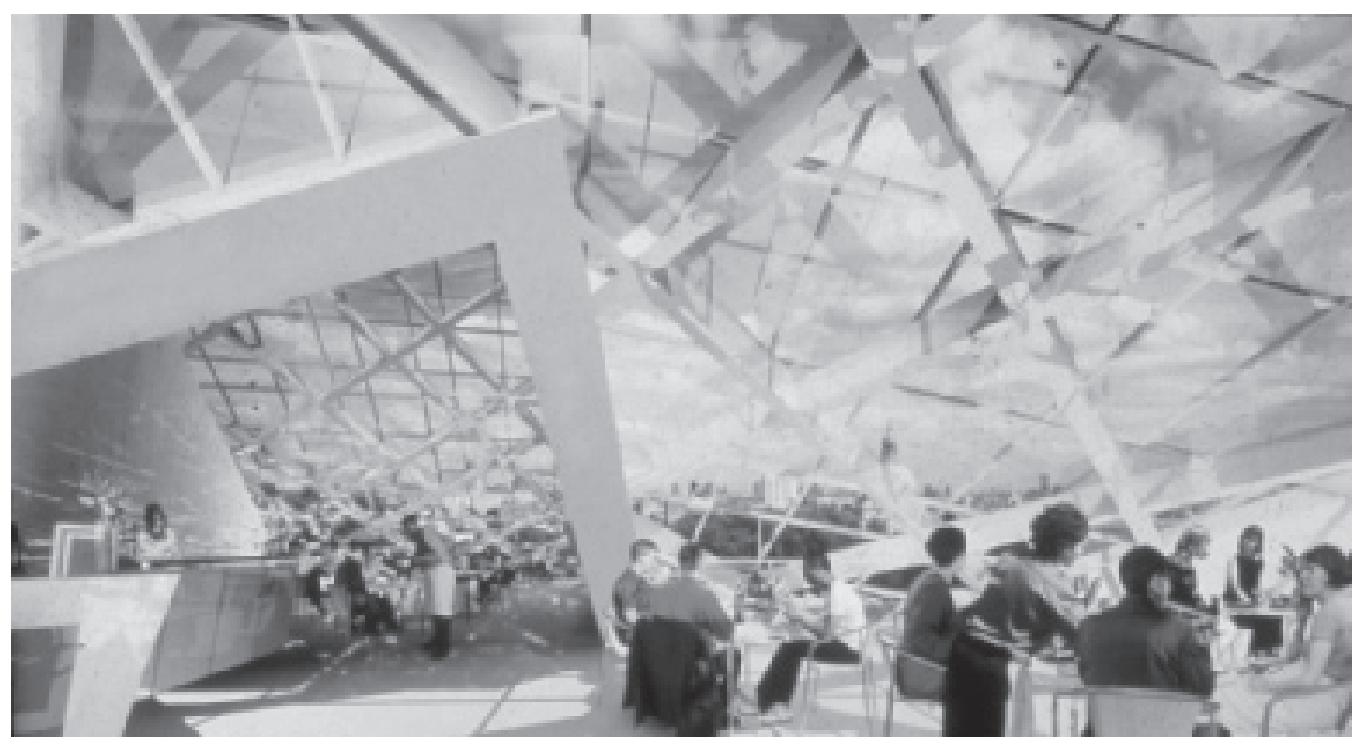

Photo montage of Spiral interior showing Level 7, Spiral Café. (C) Miller Hare 2001.

parts (the V\&A and the Science Museum) a century ago. This was an event which fractured the institution, philosophically and intellectually as well as physically. It is an irony that science museums today are more associated with "doing" and art museums more with "knowing". The separation of science and art into two museums was not part of Cole's original intention; nor is the fact that they have separated any reason why today the V\&A should not be as much about "doing" as about "knowing".

Research for the Campaign for Learning, in 1998, found that the proportion of UK adults currently and actively engaged in all kinds of learning had risen to $66 \%$. Those involved in learning mainly or entirely outside the formal education system, that is, selfdirectedly, were a high as $56 \%$ - a significant majority. ${ }^{12}$ The needs of this group are currently not adequately catered for by the statefunded education sector. The Spiral could play a particularly significant role as a centre for this kind of personal learning.

For many years, educational policy and practice was based on the assumption that, for the majority of the population, the most important learning took place in the classroom. In recent decades, as the weaknesses of schools and other formal educational institutions have become evident, that assumption has been challenged and replaced by the concept of lifelong learning. Formal education contributes to this but other kinds of learning - such as self-directed learning and informal learning - are often more important. Informal learning - the kind that begins at birth and develops throughout life through 
94 casual social interaction with other people, provides the foundation for all development. An implication of this is the need for museums to support families and community groups, which together are two of the most important sources of support for informal learning. Both of these audiences will be priority groups for the Spiral.

Learning centres such as the Spiral will be essential for the achievement of a learning society: open, cross-generational, cross-disciplinary, multiply-accessible, suited to a diversity of learning styles and types of intelligences, a forum for public debate, multi-voiced, networked and community-linked, a place of interchange and connection, a contact point for practitioners and the public; a centre for research on public learning as well as practice. It will aim to become a new kind of learning institution, a symbol of the change in educational paradigm we are experiencing. In the twentieth century, the cultural sector emerged as the second education sector; in the twenty-first century it is set to become the dominant force in learning.

A recent Crafts Council in the United Kingdom report found that $85 \%$ of secondary pupils studying art, and $55 \%$ of those studying design and technology, made some use of museum and gallery collections and museum and gallery education as resources for acquiring knowledge and understanding of the historical, technological and cultural content of a range of different kinds of crafts; $10 \%$ of pupils studying art made a lot of use. ${ }^{13}$ This on the face of it may suggest that all is reasonably well in the relationship between museums and galleries and crafts education but this would be a misleading conclusion. The report does not analyse in depth the nature and extent of pupils' use of museums - both of which are usually severely limited.

One former inspector of Art and Design in Schools in the United Kingdom has identified a significant potential role for the Spiral as a place where the production and the process of art and design are given equal value, for an education system which has neglected first one, and then the other. He believes that pupils are currently losing touch with cultural artefacts - the 1960s and 1970s in particular overvaluing process, and undervaluing product. The Spiral, he has said, can provide pupils with a social context for objects and show that they have a social purpose.

For school children, and other visitors, the Spiral must work upstream in research into learning processes, and also downstream alongside practitioners, educators, students and the general public in implementing the results. The emphasis should be on the development of skills in using museums rather than the acquisition of knowledge per sé, and on encouraging and developing talent. The Spiral will, it is proposed, be a centre of educational excellence, a centre for a network of distributed learning communities.

One of the distinctive features of the educational programmes for the Spiral will be its emphasis on services for students of art and design, design history, cultural education and a wide range of other disciplines. It is a remarkable feature of the V\&A that about one in five of all its visitors are students, mostly coming as independent users rather than in booked groups. The V\&A is, therefore, playing a unique role in the education of several hundred thousand students each year who, within a short time, will take that experience with them into their work. It is, in this sense, one of the most vocationally orientated of all 
museums, and one which makes a unique and direct contribution to the creative economy.

An important element of the Spiral is its architectural quality. The building itself is an example of the creativity in design which the Museum hopes to foster within. It will be, arguably, one of the greatest designed objects in our collections. The V\&A has a special opportunity to use the Spiral as a means to educate the public about architecture, and more particularly to exemplify the spirit and meaning of the Spiral as a public project. This work will be underpinned by development of Spiral architecture learning resources on the Web and in print, and the generation of an education programme related to Spiral projects. The aim is to foster, in the years up to its opening, understanding of the Spiral at a deeper level, and for more diverse audiences, than the media coverage which so far has been the main forum for public debate. This may be one of the first major new museum projects which has initiated an active architectural educational programme focussed on the building before it opens, rather than afterwards.

A question the Museum is now resolving is to what purpose are we educating the public? To understand, to do, to live, to teach others? About what do we educate? The decorative arts, design, architecture, visual literacy, the arts, social history, cultural education, cultural development, creative use of museums? If learning is about change through experience, what changes do we want to achieve through learning, and by and for whom? Does the development of the creative economy provide the rationale the Spiral requires for its educational work? These questions the project will debate and (at least provisionally, for our own generation) attempt to answer.
The PROGRAMME

The Spiral will operate as a major arts centre for West London (which lacks such a facility) and an arts "journal" for the world. Its changing programme of daily and weekly events and exhibitions addressing current issues will be balanced by major shows which will offer strategic analysis. As an enabling space the Spiral will be a museum of diverse voices - great art historians and thinkers, students of art and design, "taste-makers," community groups and practitioners, as well as museum staff, all mingling there.

A museum is itself a work of art, a cultural artefact, and this will be overt and explicit in the Spiral where, the Museum intends, any visitor who enters it will be aware that this is a space where the building and the programme are in harmony in defining, questioning and countering the place of the arts in our daily life. At a more experiential level no schoolchild could enter this space without taking in a breath in amazement at its extraordinary design, nor leave it without looking at the city outside and their own home with different eyes.

The Spiral through its programme will be a museum of the arts in three senses: first, the arts as contemporary creativity; second, the arts as historical creativity, to contextualise the contemporary; and third, the arts as medium of interpretation.

The programme developed by the Spiral will be in constant evolution, returning regularly to look afresh at key themes, issues and fields of practice. Innovation will be ensured by the project's emphasis on research and evaluation, by its use of specialists and practitioners from a wide range of disciplines on project teams, and other arts and educational 
96 organisations to work in partnership with the Museum to present their ideas through events and exhibitions. At any one time the Spiral will offer visitors a multiplicity of voices, sometimes in conflict with one another, and speaking with varying degrees of authority and expertise. The common elements will be the search for excellence, innovation, public participation, and authenticity of experience through contact with objects and practitioners. All will express the broad themes of the arts in everyday life.

\section{Digital technology AND MULTIMEDIA}

The burgeoning media technologies represent a new world of human experience and behaviour. Control of media production and, with it, control of the interpretative process, is moving from traditional producers to consumers, from transmitters to receivers, from experts to the public. Computers are becoming multisensory, and are rapidly becoming capable of responding subtly to human behaviour by changing services and environments.

Digital media packages at present are often imaginatively, aesthetically and educationally challenged, but this is beginning to change. The new technologies offer exceptional opportunities for individual and social learning. They will also enable people to choose when and where to use the V\&A, what resources they want, what support, and what they will create.

The Museum is investigating the potential for new kinds of orientation and educational media, which would be capable of offering ideas for activities in the Museum, changing some local environments within gallery spaces so as to allow comparison of real objects with virtual alternatives from elsewhere in the V\&A or other institutions worldwide. The digital guides would adjust to the needs of individual users, and would also be capable of recording and transmitting back to homes or colleges images, data, sounds, interpretations and other results of personal and group research. With their agreement, profiles of each user could be stored by the Museum and used to maintain and offer personalised services of news, information, sales and learning resources before or after the visit. Distance learning through Internet transmission will if possible feature on-line services.

Through technology, the Spiral will aim to make the V\&A ubiquitous throughout the United Kingdom in schools, colleges and other centres. It will also aim to extend its internal networks through study and information points in galleries.

Orientation is not a process of transferring information. It is an iterative process in which diagnosis of, and sensitivity to, user needs and interests on the part of the Museum is essential. These requirements can concern content (subject and collections) but they may also involve preferences for types of activity and social interaction. It is often more important to a family to know, for example, what kind of activities (storytelling, hallmarking etc) are on offer in, say, the Silver Gallery, than whether they are related to this spoon or that, and who was the maker of the spoon, on which date, and from which workshop.

At present this diagnostic process is undertaken by people. New visitor-responsive media technologies may enable the Museum to question, analyse, suggest and advise electronically; they potentially could do this for every visitor, throughout the visit, and in every gallery or other public space; and do so in an 
increasingly individual human way. The Spiral could, then, be at the centre of a neural network of knowledge, expertise and learning support, providing some existing services to a standard which is not possible at present, and providing many others which the V\&A cannot provide in such a strategic and integrated way anywhere else but in the new building.

The Spiral will, it is hoped, also be in the forefront of developing digital technologies as an art form - that is, technologies that stimulate creative thinking, personal and social development, aesthetic awareness, play, and meaning making, rather than simply the storage and transmission of (for most people, relatively useless and inaccessible) data.

\section{OUTREACH: ROOTS AND ROUTES}

In his book Routes, James Clifford begins with the "assumption of movement, arguing that travels and contacts are crucial sites for unfinished modernity. The general topic... is a ...view of human location as constituted by displacement as much as by stasis, concerned with human difference articulated in displacement, tangled cultural experiences, structures and possibilities of an increasingly connected but not homogeneous world." 14

In seeking as he sees it to redress the balance in favour of travel and translation, interacting and heterogeneity, and through his critique of continuity, Clifford in turn opened himself to criticism that he was an apologist for global capitalism, who tries to represent its destructive effects as themselves a natural and continuous part of the universal human condition, and whose denial of the rootedness of human societies is itself a form of Western, and especially American, romanti- cism. The debate is of significance to museums (including the Spiral) in as much as they are conscious of (and seek to critically evaluate) their role in their communities as ethnographers of contemporary culture, repositories of memory, and other active and developmental cultural responsibilities. As a space for contemporary practice of art, craft and design, and a part of the V\&A which may explicitly embrace a global (as opposed to an imperial) definition of the disciplines it represents, the Spiral could be an exemplar of the Cliffordian principles of cultural heterogeneity and hybridity.

On the other hand, museums can exercise more control over their destiny and discourse than the individuals who are the main focus for Clifford's essays. Museums, especially national museums such as the V\&A, can choose the degree to which they merge with their communities and the changes they experience, or stand apart as engaged or disengaged participants/observers. The barriers between museums and their communities expressed as professional practice (collecting, conserving, researching, displaying, interpreting) and articulated in concepts of professional expertise - are largely of museums' own making. All are open to review and redefinition.

The journal Museum Practice in 1996 identified three types of outreach: object-based, that is, displays of objects for educational or other uses; activity-based, the use of museums as the starting point for activities such as workshops, reminiscence, theatre, or field work; and information-based, dissemination of information about museum subjects and collections through media such as travelling exhibitions, posters, broadcasting and the Internet. 
As Museum Practice points out, outreach raises some important issues. Does outreach work relate to the wider strategy of the institution? Are there potential partners in the field of activity chosen by the museums? Is it a genuinely two way process, with the museum itself willing to change in response to community needs? Has the museum got the resources to sustain its commitment? Is that commitment integral to the future of the museum or a tactical add-on? ${ }^{35}$

Much of what is recommended in the journal would be identified by museum workers as essential components of good practice. However, this approach does not go far enough in the view of some adult and community specialists. Professor Lalage Bown, (a distinguished adult education academic with a longstanding connection with the museum sector and a specialist in adult education methodologies in non-Western societies) is critical of the concept of outreach. She believes it is founded on the principle that "we have it and you don't" and so reinforces rather than subverts the unequal power relations between museums and communities. More important than outreach, she says, is inreach; communities should be rooted in their museums as well as museums in their communities. ${ }^{16}$ This is a step further than most museums are yet prepared to go, because it challenges long established concepts of authority, expertise, and value; it requires changes to the way museums create exhibits and other public resources on-site; and it implies the need for new and more flexible, and inclusive organisational structures, which reflect the need for closer integration of "inside" and "outside" activities.

The Spiral will need to establish an ongoing programme of community-based initia- tives with priority audience groups, in association with artists, craftspeople and other practitioners, which in turn may generate a regular programme of on-site and touring exhibitions. There are at least two reasons for adopting such a model. First, it is a highly cost-effective way to generate innovative exhibitions that ensure a diversity of voices are represented in Spiral shows; second, it will provide a foundation for other national initiatives within the sector.

\section{RESEARCH AND EVALUATION}

Without research there can be no innovation. Therefore, research has been an urgent priority and central to the working methodologies of the project team from the Spiral's first inception. For the same reason, it will be an integral part of the process of development and operation of the new building. However, research for this project is not conceived only in terms of the work of staff. The Spiral will, the Museum intends, also recognise that the public - of all ages and levels of skills and understanding - are not the passive recipients of the knowledge generated by staff, but themselves contribute to and use the Museum for study and research purposes. Whether the users are academics, postgraduate research students, adults with an amateur but sustained interest in a museum-related subject, a family, school children engaged on a project, or teachers or tutors planning a group visit, all need the opportunity to build on what they see in the galleries through further study.

Like any other museum, had the V\&A relied only upon its own expertise in isolation, the Museum could never have developed as it has done, indeed could never have come into existence in the first place. It is self-evi- 
dent that research is a collaborative exercise between the museum and its public. A thriving research community in the future in any field, and the achievement of excellence at its cutting edge, depends not just upon investment at that point of excellence but also in the schools, communities and other grass root organisations that are the seedbeds for future development.

The Spiral will be a centre for research for the Museum and will provide a test bed for new methods of public engagement with the arts. The project will also, we hope, be an important focus for development of reflective practice. Theory and practice should not separate endeavours but interdependent and mutually enriching activities.

Reflective practice often does not conform to the conventions of published research and usually is not published at all. Like much of curatorial expertise, the practical research and study conducted by museums and gallery educators, college tutors, teachers, families and others is often ignored by museums because it is handed on through demonstrations of good practice and the formal or informal apprenticeship of others. The Spiral will, it is planned, offer demonstrations, apprenticeships or other practical and social approaches to the development of skills and knowledge, as research activities.

In his article, "Research and Design", Professor Christopher Frayling proposes three categories of art and design research. The first, research into art and design, he says is well established and encompasses historical, theoretical, sociological, perceptual and other studies of art. The second, research through art and design, is concerned with how results are achieved and communicated through art, design or craft activity itself. The third, re- search for art and design is defined as research where the end product is an artefact - where the thinking is embodied in the artefact, and (unlike in the second category) the goal is not "necessarily communicable knowledge in the sense of verbal communication, but in the sense of visual or iconic or imagistic communication." 17 In practice the three categories are not always separable. The V\&A has, through its emphasis on research into materials and techniques and the design process, a tradition of taking a broader approach to art and design research. The Spiral will continue and extend that tradition.

The Museum's intention is to ensure that the Spiral itself, when it opens, will be a living research centre: both a place for research and, through its public programmes, the subject of research. All parts of the building will be informed by this principle. We also aim to establish the site as a centre for research on creativity and innovation in the arts - how to make change, and improve and renew cultural institutions - not as a project, or a one year or five year initiative upon opening, but as an ongoing methodology. The Spiral must avoid the intellectual stasis and isolation of traditional museums; it must constantly bring in new ideas, and stimulate the disciplinary cross-fertilisations which made the project possible in the first place.

This will have a number of practical implications. First, the V\&A will seek partnerships - and particularly more strategic partnerships - with other organisations whose blends of skills and expertise complement those of the Museum. Secondly, the Museum will make the use of demonstration projects and prototyping a standard procedure in it, as it has already done in the British Galleries. Third, it will establish an ongoing and strategically 
100 planned programme of research on key themes, which might include: design in everyday life; the making society/the creative society; informality, interactivity and participation in art and design; research as a tool for creativity for artists/craftspeople and designers; how non-professionals study art and design; or public understanding of design.

Work in progress will be constantly moving out into the public sphere, from closed to open, or from the outside to the inside, as it emerges from makers and/or community groups into the open spaces in the Spiral, and then spawns further creative specialist, educational and community activity.

\section{Notes}

1. David Alexander and Ian Martin, Competence, Curriculum and Democracy, in Marjorie Mays and Jane Thompson (eds.), Adult Learning, Critical Intelligence and Social Change, National Institute for Adult Continuing Education, Leicester, 1995, pp82-96

2. Edward W. Soja, Thirdspace: Journeys to Los Angeles and other real-and-imagined places, Blackwell, Oxford, 1996, pp30-31, 313-4.

3. Anthony Burton, unpublished V\&A document, 1998

4. Crafts Council, Learning Through Making, London 1995

5. Hans Eysenk, The measurement of creativity in Margaret Boden (ed.) Dimensions of Creativity, Massachusetts Institute of Technology Press, Cambridge Mass., 1996, pp199-242
6. Mihaly Csikszentmihalyi, Creativity: Flow and the psychology of discovery and invention, Harper Perennial, New York, 1997, pp51-76

7. Leslie Perry, The Educational Value of Creativity in Journal of Art and Design Education, vol. 6, no.3.

8. Karen Raney, Visual Literacy. Arts Council of England: London: p24

9. Csikszentmihalyi, op cit, pp127-147

10. Chris Smith, Consulting on NESTA in RSA Journal, November/December 1997, p47

11. Henry Cole, quoted in David Anderson, A Common Wealth: Museums in the Learning Age. The Stationary Office, London, 1999, p93.

12. Attitudes to Learning '98, Campaign for Learning, London, 1998, p.11

13. Crafts Council, Pupils as Makers, Crafts Council and Roehampton Institute, London, 1997

14. James Clifford, Routes: Travel and translation in the late Twentieth century, Harvard University Press, Cambridge, Massachusetts, 1997, p2

15. Museum Practice, vol. 1, issue 3, London, 1996

16. Lalage Bown, unpublished presentation at the colloquium, "Adult non-formal learning through museums", held at Birmingham Museum of Science and Industry on 10 July 1995

17. Christopher Frayling, Research in Art and Design, in Royal College of Art Research Papers, vol 1, 1993

\section{David Anderson}

Director of Learning and Interpretation

Adr: Victoria and Albert Museum, South Kensington,

London SW7 2RL England

Fax: +4479422193

E-mail:d.anderson@vam.ac.uk 